\title{
Impact of psychological ownership on the performance of business school lecturers
}

\begin{abstract}
The purpose of the present article is to investigate the impact of psychological ownership, job performance, job commitment, and job satisfaction among business school lecturers of public universities in Malaysia. As psychological ownership is a relatively new concept, the present study expands the use of it in a different setting. Based on the correlation analysis, it was found that psychological ownership had significant and positive relations with job commitment, job satisfaction, and performance. The findings of the present study can help the management of universities select the lecturers with a right attitude and provide them with a right environment to perform better.
\end{abstract}

Keyword: Job commitment, Job performance, Psychological ownership, Malaysia 